\title{
Atrial Fibrillation, CTCAE
}

National Cancer Institute

\section{Source}

National Cancer Institute. Atrial Fibrillation, CT CAE. NCI Thesaurus. Code C54767.

A disorder characterized by a dysrhythmia without discernible $\mathrm{P}$ waves and an irregular ventricular response due to multiple reentry circuits. The rhythm disturbance originates above the ventricles. 